\title{
An Analysis of Innovation in Entrepreneurship and its link to Sustainable Development Goals
}

\author{
Serah Kalambo Mbetwa
}

\begin{abstract}
Innovation and Entrepreneurship is an economic engine of any economy especially developing nations. A need therefore exists to understand entrepreneurship in the context of innovation and sustainable development goals. It is important to note that most entrepreneurs in Africa have failed to embrace innovation in its totality and as a result most businesses are unable to cope with the technological changes that are taking place every day. Therefore the cost of doing business has gone up. For example, entrepreneurs stick to the old ways of doing business instead of using new technologies to enhance business. Such businesses fail to cope with the ever changing world and subsequently lose market and wind up. It is sad to note that in Zambia for example most companies have scaled down due to high cost of doing business.
\end{abstract}

In bettering the lives of the people, the United Nations have developed 17 sustainable development goals. In crafting their business strategies, entrepreneurs should therefore be alive to these goals to maximize their potential and therefore be regarded as being sustainable.

\section{Significance of the Study}

The significance of the study is to allow the researchers to understand the linkages between innovation, entrepreneurship and sustainable development goals. It will also help us to be aware about the need to embrace innovation and achieve better living through the embracing of sustainable development goals.

\section{Design/methodology}

Secondary data collected mostly through literature reviews showed that entrepreneurs in developing countries are resilient; however, most of these businesses are not managed sustainably and hence wind up. This can be attributed to the fact that most of them lack innovation necessary to move the businesses forward and fail to adapt to the many technological changes that are taking place every day.

\section{Findings \\ The findings revealed that entrepreneurship and innovation management are linked for any successful business. Innovation and sustainable development in developing countries are fundamental to any form of any enterprise. A combination of the innovation and entrepreneurship coupled with the embracement of sustainable development goals holds the key to organizational sustainability in this period of rapid change.}

Serah Kalambo Mbetwa

Information and Communications University

Zambia

Richard Silumbe

Information and Communications University Zambia

\begin{abstract}
Value
This paper will benefit various stakeholders especially those with an entrepreneurial mind. Our view on business organisation and innovation will change. For the authors, the primary value of this paper is the opportunity to learn about the linkage between entrepreneurship and innovation and how sustainable businesses will impact on business and the economy at large. The authors believe, this research paper will add value to the existing body of knowledge in terms of academics and practical aspects. It will also add value to the existing body of academicians, researchers and the business men and women around the globe. Entrepreneurship will be seen as tool for innovation and that environmental changes must be managed if any business is to be a success.)
\end{abstract}

Keywords- Economy, Entrepreneurship, Innovation, Sustainable Development

\section{Introduction}

\section{A. Background}

Entrepreneurship is a key player and powerful engine that drives today's global economy. The influence of entrepreneurship on expansion and promotion of productive activities in every sphere of economic life has made it become a significant wheel of economic growth and development. Africa has not been left behind in embracing entrepreneurship as vehicle for economic growth. The continent is increasingly taking global stage for growth and opportunity. African states are continuously encouraging entrepreneurial activities to take center stage in order to create more jobs and raise the living standards of many Africans.

However, entrepreneurial activities keep on changing due to technology advancements. The technology revolution is forcing every entrepreneurial activity to conform to new ways of doing things especially that the world has become a global village due to globalization. Africa, on the other hand, is finding it difficult to catch up with new innovative ideas due to fast-paced technology changes. It is evident that Africa is lagging behind in incorporating technology where business activities are concerned.

According to United Nations` 17 sustainable development goals, technology plays key part in ensuring development in developing countries. The United Nations [1] states that without technology and innovation, industrialization will not happen, and without industrialization, development will not happen. Goal 9 of the sustainable development goals highlight the fact that around 40 percent of firm productivity in African countries is affected as a result of constraints in infrastructure. Furthermore, energy use in Organization for Economic Cooperation and Development (OECD) countries will continue 
to grow another 35 percent by 2020 despite technological advances that have promoted energy efficiency gains. Thus, goal number 12 target emphasizes support for developing countries to strengthen their scientific and technological capacity to move towards more sustainable patterns of consumption and production.

\section{B. Objectives}

- To study the impact of innovation on entrepreneurial activities and business success

- To establish the linkage between innovative entrepreneurship and sustainable development goals

\section{Theoretical framework}

\section{The economic theory}

The economic theory emphasizes the importance of applying good judgement to economic decisions which is regarded as a specialization of entrepreneurs. Volatility drives the demand for entrepreneurship in an economic environment whilst economic incentives are the main motivators for entrepreneurial activities.

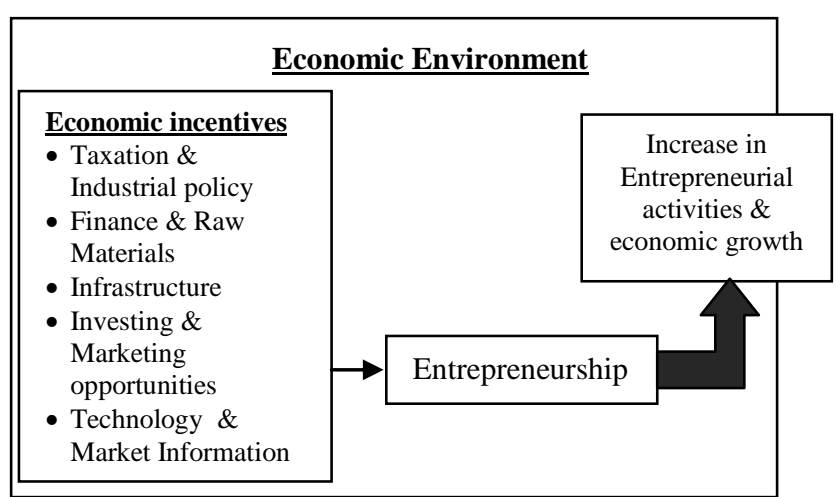

Figure 1: Economic theory

\section{Entrepreneurship innovation theory}

According [6] an innovative and creative entrepreneur plays a vital role in the process of economic development. Schumpeter's theory emphasizes on innovation which is as a result of new products, new production methods, new markets, new forms of organization. He further explains that wealth is created when such innovation results in new demand.

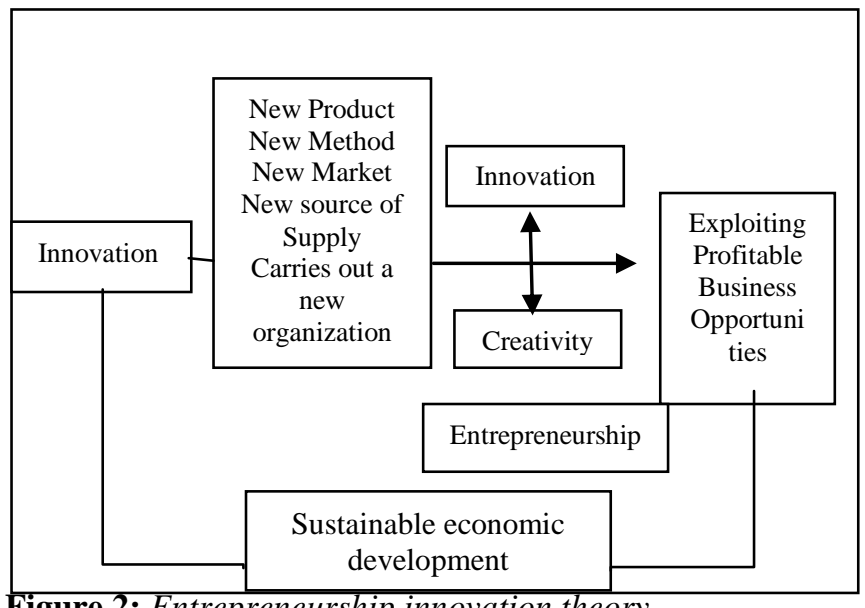

Figure 2: Entrepreneurship innovation theory

\section{Acronyms}

ICT Information and Communication Technology

ILO International Labour Organization

MSME Micro, Small and Medium Enterprise

OECD Organization for Economic Co-operation and Development

UN United Nations

\section{Literature Review}

\section{Entrepreneurship and Innovation}

According to [2] entrepreneurship, in its narrowest sense, involves capturing ideas, converting them into products and/or services and then building a venture to take the product to market. But studies show that there is considerable overlap between entrepreneurship and innovation [3-5]. Entrepreneurs use innovation, an entrepreneurship tool, to exploit change as an opportunity for a different business or service. [6] Adds that innovation has to address market needs, and requires entrepreneurship if it is to achieve commercial success. Such a broad understanding of innovation is particularly meaningful within the context of innovative entrepreneurship to the extent that upgrading technology or improving skills may lead to more efficient uses of resources or higher-quality outputs.

\section{Sustainable development}

The world governing body, United Nation, has recognized the influential role entrepreneurship plays in sustaining development. At the United Nations Conference on Sustainable Development, held in Rio de Janeiro, Brazil, in June 2012, world leaders recognized the important contribution that entrepreneurship can make to sustainable development by creating jobs, driving economic growth and innovation among others. Stressing the importance of giving appropriate consideration to the promotion of entrepreneurship in the post-2015 development agenda, the General Assembly emphasized the need for partnership with private sector; and invited Member States to strengthen entrepreneur-promotion initiatives in six priority areas.

Furthermore, it encouraged countries to consider establishing or strengthening national centers of excellence in entrepreneurship, and called upon the United Nations systems to recognize entrepreneurship and integrate its various forms into policies, programs and reports and to support national efforts in that regard, as appropriate.

Further to General Assembly decision 67/555, entrepreneurship formed an integral part of Open Working Group`s discussion on Sustainable Development Goals established in 2013. Thus, entrepreneurship was incorporated in a variety of targets proposed by the Open Working Group.

The role of entrepreneurship in addressing sustainable development challenges 
Entrepreneurship has a critical role to play in sustainable development and poverty eradication. It has the potential to stimulate economic growth through opportunity and job creation; help formalize businesses; and strengthen local productive capacity by developing linkages with transnational corporations and thereby indirectly maximize the impact of foreign investment. It also has the potential to contribute to social development by promoting social and environmental entrepreneurship and gender equality [1].

Entrepreneurship can also have a significant impact on job creation. According to [7] projections, 500 million new jobs will need to be created by 2020 in order to provide full employment. Developing countries will require more than 90 per cent of these jobs, presenting an unprecedented challenge for countries. In low-income countries, the share of jobs created by small and medium-sized enterprises is even higher ( 80 per cent). Developing countries, however, lack high- growth, medium-sized enterprises - "gazelles" - which outperform other firms both in productivity and in creating employment. Technology hubs, incubators and science parks have been established in many countries as a way to boost the creation of high-growth firms.

\section{Global perspective}

[8] indicated a number of Arab countries whose governments have tried to promote entrepreneurship and succeeded to some extent. Arab countries have, in general, invested a lot in the Information and Communication Technology (ICT) sector. This has helped organizations in the region to modernize their operations and up-grade their performance. Arab citizens have also been positively affected by new ICT devices and services and their use is widespread. However, while these governments have restructured legal systems, eased the procedures for starting businesses, and enhanced science and technology education and training, entrepreneurship education has much lagged behind. In agreement, various authors and researchers on technological entrepreneurship have proposed studies on technological innovation as an evolutionary approach that aims to solve the problem of technological innovation from a cultural perspective and social development. In agreement, various authors and researchers [9-11] on technological entrepreneurship have proposed studies on technological innovation as an evolutionary approach that aims to solve the problem of technological innovation from a cultural perspective and social development [12-13].

\section{African Perspective}

[14] Carried out a research work to examine the impact of innovation on the entrepreneurial success in business enterprises in Nigeria. The study proved that innovation has a significant and positive relationship with product quality and corporate image. The research concluded that engaging in innovative activities will achieve bumper success in many entrepreneurial ventures.

\section{Zambian Perspective}

[15] Reports that technology advancements and innovative ideas are to be prioritized in order for productivity of Zambian businesses are to improve. According to the survey, transportation, infrastructure and access to financial services are serious constraints to business operations. Innovative approaches are encouraged to provide financial services and improve ICT infrastructure and increase productivity especially among the Micro, Small and Medium Enterprises (MSMEs). In an earlier research, [16] reveals that most MSMEs in Zambia venture into business to supplement other income while very few enterprises are established with a motive to try out new business ideas. This has limited the country's potential to realize innovative business ideas into successful enterprises with a wide and unique product range.

\section{Methodology}

The methodology used for this paper was secondary analysis. Secondary analysis is the use of existing data to investigate research questions other than the main ones for which the data were originally gathered. Secondary analysis is an empirical exercise that applies the same basic research principles as studies utilizing primary data and has steps to be followed just as any research method [17]. This approach to using existing data sets has the advantage of greatly reducing the time and cost of doing research even though provides little or no control over the study population, design, or measurements [18-19]. In addition, a qualitative approach method approach was used to gather data

\section{A. Design}

Research design, according to [20], is best described as the overall plan, according to which the respondents of a proposed study are selected, as well as the means of data collection or generation. In this paper, meta-analysis design was adopted which is an analytical methodology designed to systematically evaluate and summarize the results from a number of individual studies, thereby, increasing the overall sample size and the ability of the researcher to study effects of interest [21].

\section{B. Justification of Design}

[22] Describes meta-analysis as one of the most important social developments in in the second half of the $20^{\text {th }}$ century. In addition, meta-analysis design provides a means of reviewing research published about a particular topic over an extended period of time and from a variety of sources. Moreover, for this paper to meet its objectives, the four steps of meta-analysis i.e. identify all relevant studies, assess study quality, deal with study heterogeneity, and summarize the results had to be applied [23].

\section{Sampling technique and sample size}

Data from diverse studies were synthesized to arrive at a summary estimate. The steps of meta-analysis are similar to that of a systematic review and include framing of a question, searching of literature, abstraction of data from individual studies, and framing of summary estimates and examination of publication bias [24].

\section{Data Collection and Analysis}

[25] states that analyzing and investigating literature is an acceptable form of desk-based research that compares the works of different authors. Aggregate data was compiled from the published studies highlighted under literature review. Under data analysis, abstraction of data from individual studies was carried out and, thereafter, summary estimates were framed. 


\section{Results and findings}

It is likely that there was room for publication bias as results are based on a selection of studies and a systematic exclusion of studies that are nonetheless important, small or unpublished. Nevertheless, the findings show that innovation in entrepreneurship, with the aid of technology, plays a key role in sustaining businesses. The findings further shows that Africa's challenge has been the application of innovative approaches in entrepreneurial activities.

The findings also establish the linkage between innovative entrepreneurship and successful business. The analysis of literature shows that innovation and sustainable development in developing countries are fundamental to any form of any enterprise.

\section{v. Conclusions and Recommendations}

\section{A. Conclusions}

In order to achieve economic development, developing countries have tried a myriad of approaches over the years. Like in developed countries, entrepreneurship has the potential to be the engine of economic growth through the impact of technology and innovation and the allocation and mobilization of the factors of production. In many of the developing countries entrepreneurship is already important and prevalent in their economies. However, the forms of entrepreneurship and the volume may be problematic for growth. For instance, close to 60 percent of Zambian MSME owners have limited access to finance posing a serious constraint to their operations. Therefore, lack of innovative ideas to sustain the business once it starts and lack of collateral for easy access to funding posse as serious challenges to attaining sustainable development. Therefore, innovative entrepreneurship can positively impact economic growth and development and significantly contribute to the achievement of sustainable development goals.

\section{B. Recommendations}

There is need for innovative approach to address the prevailing challenges. Policymakers need to adopt targeted approaches to reduce the constraints by complimenting more nuanced approaches that take into account the needs of entrepreneurs in all sectors - ranging from hard infrastructure such as energy, water and transport to soft infrastructure such as education, finance and investment climate reform

The study depended on secondary data set to analyse and make conclusions on the subject matter. Therefore, field studies that will have control on study population, design and measurements should be conducted

\section{Acknowledgment}

I would like to acknowledge Dr. Richard Silumbe, the Program Coordinator at the Information and Communication University. I would also to acknowledge Mr. Michael Kaziya whose valuable input has made this work a success.
In addition, I would like to acknowledge IRED for the opportunity to participate in this conference.

\section{References}

[1] United Nations, "Sustainable development: Entrepreneurship for development" report of the Secretary General, 2014

[2] Johnson, D. What is innovation and entrepreneurship? Lessons for large organizations. Industrial and Commercial Training, 33(4), 2001, pp. 135-140.

[3] Kanungo, R.N.. Entrepreneurship and innovation: Models for development. International Journal of Entrepreneurial Behavior \& Research, 5(4), 1999.

[4] Drucker, P.F. Innovation and entrepreneurship: Practice and principles. London: Heinemann, 1994.

[5] Schumpeter, J. The theory of economic development. Harvard (reproduced, New York 1961), 1934.

[6] Zhao, Entrepreneurship and innovation in e-business: An integrative perspective. International Journal of Entrepreneurship and Innovation, 6(1), 2004, pp. 53-60.

[7] International Labour Organization, Global Employment Trends 2014: Risk of a Jobless Recovery? (Geneva, 2014).

[8] Morrison J. International business environment: Global and local marketplaces in a changing world. Palgrave MacMillan: New York, 2006.

[9] Zahra S, Bogner W. Technology Strategy and Software New Venture Performance: The Moderating Effect of the Competitive Environment. Journal of Business Venturing 15: 2000, pp. 135-173.

[10] Zahra SA, Gerard G. International entrepreneurship: The current status of the field and future research agenda. Entrepreneurship Theory and Practice 41: 50. 2003.

[11] Richtermeyer G. Emerging themes in entrepreneurship research, Business Research and Information Development Group (BRIDG). Outreach and extension, University of Missouri, Lincoln University 2003, pp. 29.

[12] Florida, R. The Rise of the Creative Class, Basic Books, New York, 2002.

[13] Parnell JA Global Entrepreneurial Strategy. In: Carraher (ed.) International Entrepreneurship, 2006.

[14] Ojo, O. D., Petrescu, M., Petrescu, A. G. and Bîlcan, F. R. Impact of innovation on the entrepreneurial success: Evidence from Nigeria. African Journal of Business Management. Vol. 11(12), 2017, pp. 261265 ,

[15] The Zambia Business Survey. The profile and Productivity of Zambian Businesses: Summary Report June 2010

[16] The Zambia Business Survey. The profile and Productivity of Zambian Businesses, 2007.

[17] Johnston, M., P. Secondary Data Analysis: A Method of which the Time Has Come. Qualitative and Quantitative Methods in Libraries (QQML) 3:619-626, 2014

[18] Doolan, D. M., \& Froelicher, E. S. Using an existing data set to answer new research questions: A methodological review. Research and Theory for Nursing Practice: An International Journal, 23(3), 2009, pp. 203-215.

[19] Dale, A., Arbor, S., \& Procter, M. Doing secondary analysis. London, UK: Unwin Hyman, 1988.

[20] Welman, C., Kruger, F. and Mitchell, B. Research methodology. Cape Town, Oxford University Press, 2009.

[21] University of Southern California Libraries. Organizing Your Social Sciences Research Paper: Types of Research Designs, 2016.

[22] Shadish, W., Cook T. and Campbell D. Experimental and quasiexperimental designs for generalized causal inference. Boston: Houghton-Mifflin, 2002.

[23] Cook D. J., Sackett D. L. and Spitzer W. O. Methodologic Guidelines for Systematic Reviews of Randomized Control Trials. J. of Clinical Epidemiology 48, 1995, pp. 167-171.

[24] Thornton A. and Lee P. Publication bias in meta-analysis: its causes and consequences. Journal of clinical epidemiology, 53(2):207-216, 2000 
Proc. of the Sixth Intl. Conf. Advances in Social Science, Economics and Management Study - SEM 2018 Copyright $@$ Institute of Research Engineers and Doctors, USA .All rights reserved.

ISBN: 978-1-63248-151-1 doi: 10.15224/978-1-63248-151-1-53

[25] Hart C. Doing a Literature review: Releasing the social science research imagination. London, UK: Sage Publication, 1998.

About Author (s):

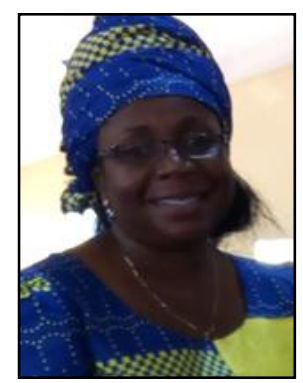

In bettering the lives of the people, the United Nations have developed 17 sustainable development goals. In crafting their business strategies, entrepreneurs should therefore come alive to these goals in order to maximize their potential and realize sustainability. 